J. Amer. Soc. Hort. SCI. 119(1):70-73. 1994.

\title{
Changes in Polyamine Content during Dormancy in Flower Buds of 'Anna' Apple
}

\author{
Shiow Y. Wang and Miklos Faust \\ Fruit Laboratory, Beltsville Agriculture Research Center, Agriculture Research Service, U.S. Department \\ of Agriculture, Beltsville, MD 20705
}

Additional index words. endodormancy, putrescine, spermidine, spermine

\begin{abstract}
Polyamine, putrescine, spermidine, and spermine contents were determined during endodormancy in the buds of low-chilling-requiring 'Anna' apples (Malus domestics Borkh.). Putrescine, spermidine, and spermine contents increased greatly in buds when their chilling requirement was satisfied. Polyamine biosynthetic inhibitors $\alpha$-difluoromethylarginine (DFMA) or $\alpha$-difluoromethylornithine (DFMO) reduced bud break and bud growth in concert with decreased polyamine titers. DFMO or DFMA did not inhibit bud break when it was applied to buds after they received the full chilling requirement. DFMO was more inhibitory than DFMA. The polyamine requirement was much higher for bud growth and bud development than during differentiation and bud break.
\end{abstract}

The flower buds of temperate-zone fruit trees, including apple, are initiated during the previous growing season. During late fall, fruit trees enter a dormant period termed endodormancy (Lang et al., 1985), during which there is little visible activity in the tissues. However, the buds are metabolically active (Zimmerman and Faust, 1969) and continue their development during the entire winter (Abbot, 1970). Bud development during winter is cultivar-dependent (Cole et al., 1982) and appears to be controlled by several factors. Chilling is required to break the dormancy. The chilling lengths required vary with cultivar. After chilling is completed, buds may still be dormant due to conditions imposed by environmental factors. Buds resume growth only when environmental conditions are conducive to growth.

Polyamides have been described as growth promoters in higher plants. Polyamides may be required by some cellular processes in the growth phase and may act as secondary messengers in the stimulation and regulation of nucleic acids and protein synthesis (Bagni et al., 1980; Galston, 1983). Polyamides also are involved in morphogenesis (Evans and Malmberg, 1989) and may be a factor in bud break. In dormant Helianthus tuberosus L., polyamides are present only in trace amounts but increase 10-to 20-fold when dormancy is broken (Bagni et al., 1980). Rapid increase in polyamides also was reported in the breaking of dormancy and initiation of potato (Solanum tuberosum L.) tuber sprouting (Kaur-Sawhney et al., 1982). In cherry (Prunus avium L. and $P$. serrulata Lindl.) flower buds, polyamides (putrescine, spermidine, and spermine) are present in all stages of bud development (Wang et al., 1985). The concentrations of putrescine, spermidine, and spermine and the total polyamine concentration in the buds of $P$. avium and $P$. serrulata are low during dormancy, but increase rapidly with the onset of active metabolism. There is no evidence that the exogenous application of polyamides can overcome rest in temperate woody perennials. The study reported here was conducted to determine the possible correlation between chilling requirement and polyamine involvement during the breaking of dormancy in apple buds.

Received for publication 27 May 1992. Accepted for publication 20 May 1993. The cost of publishing this paper was defrayed in part by the payment of page charges. Under postal regulations, this paper therefore must be hereby marked advertisement solely to indicate this fact.

\section{Materials and Methods}

Flower buds of 'Anna', a low-chilling-requiring cultivar, were used. Shoots were collected in October 1991, defoliated, wrapped in plastic, and stored in a room maintained at $4 \mathrm{C}$. Each hour at $4 \mathrm{C}$ was considered 1 chilling unit (CU). After the shoots had received 0, 200,400, or $600 \mathrm{CUs}, 10 \mathrm{nmol}$ of the polyamine biosynthesis inhibitor $\alpha$-difluoromethylarginine (DFMA) or $\alpha$-difluoromethylornithine (DFMO) was dissolved in deionized $\mathrm{H}_{2} \mathrm{O}$ and injected directly with a syringe into the tips of each bud, without disturbing the flower primordia. Buds then resumed chilling up to 600 CUs. Control buds were injected with $\mathrm{H}_{2} \mathrm{O}$ only. Each treatment used 350 buds. Shoots were held for 3 weeks with their basal ends in glass jars containing distilled water at 22 to $24 \mathrm{C}$ so that budbreak and bud growth could be observed. The basal ends were recut and the water was changed at 3-day intervals. Stages of flower bud development were classified according to Westwood (1978). Flower buds were considered to have broken dormancy when buds reached the green-tip stage.

After buds received specified CUs and polyamine inhibitors (DFMA or DFMO), the scales were removed leaving the partially or fully developed flower clusters intact. Triplicate samples of 0.5 $\mathrm{g}$ of flower buds were collected at each sampling time. Each sample was extracted one at a time with $4 \mathrm{ml}$ of $5 \%$ ice-cold perchloric acid using a chilled mortar and pestle. 1,8-Octanediamine (Sigma, St. Louis) (150 $\mathrm{nmol} \cdot \mathrm{g}^{-1}$ fresh weight) was added as an internal standard. The homogenate was then centrifuged at 20,000x $\mathrm{g}$ for $20 \mathrm{~min}$ and the supernatant was removed for polyamine analysis.

Polyamides were analyzed using high-pressure liquid chromatography (HPLC) with methods similar to those described by Kramer and Wang (1989). Dansylation was performed by mixing $400 \mu \mathrm{l}$ of $10 \mathrm{mg} / \mathrm{ml}$ (in acetone) dansyl chloride (Sigma) and 150 $\mu \mathrm{l}$ saturated sodium bicarbonate with 200@ of extract. After the samples were incubated overnight at room temperature, 250@ of $50 \mathrm{mg} / \mathrm{ml}$ proline was added and incubation resumed for another hour. After centrifugation for $10 \mathrm{~min}$ in a microcentrifuge (Eppendorf, Westbury, N.Y.), the $\mathrm{pH}$ of the supernatant was checked and adjusted as necessary to maintain neutrality (6 to 8 ). HPLC analysis was performed using $25 \mu \mathrm{l}$ of the supernatant on a system consisting of two pumps (model 6000A; Waters, Milford, Mass.). Samples were injected using an injector (model U6K; Waters) onto a reverse-phase C- 18 column (25-cm LC- 18 with a Supelguard LC-18 5- $\mu \mathrm{m}$ guard column; Supelco, Bellefonte, Pa.). 
Samples were eluted from the column at a flow rate of $1.5 \mathrm{ml} \cdot \mathrm{min}^{-1}$ with a programmed solvent gradient of $0,100,0 ; 15,0,100 ; 19,0$, 100; where the first number is the time (minutes), the second number is the percentage of buffer A (60 methanol: 40 water), and the third number is the percentage of buffer B (100\% methanol). Elution was completed in $18 \mathrm{~min}$. Eluates were detected by a spectrofluorometer (model 650-10S; Perkin-Elmer, Norwalk, Corm.) using an excitation wavelength of $365 \mathrm{~nm}$ and an emission wavelength of $510 \mathrm{~nm}$. The pumps were controlled and the data were collected and analyzed using a NEC APCIV PowerMate 2 computer system equipped with a Maxima 820 chromatography workstation (Dynamic Solutions, Ventura, Calif.). Polyamides were quantitated by comparing peak areas with those of standards.

\section{Results and Discussion}

The main polyamine in apple flower bud was putrescine, although putrescine, spermidine, and spermine are present at all stages of bud development (Fig. 1). Cadaverine is a minor component and present in trace amounts only (data not shown). In higher plants, polyamine metabolism has been associated with the action of plant growth substances and the regulation of plant growth and development (Faust and Wang, 1992; Galston, 1983). Control buds receiving $0,200,400$, or 600 CUs resulted in $92 \%$ bud break (Fig. 2). It is not certain how chilling overcomes endodormancy (Powell, 1986), but there is evidence that metabolic events take place in apple buds when they are forced to terminate dormancy and resume growth (Wang and Faust, 1989; Wang et al., 1991ad). An increase in polyamine titer was observed in buds after they had been chilled. Buds receiving 200 CUs contained higher amounts of putrescine, spermidine, spermine and total polyamines than buds receiving 0 CUs (Fig. 1). Polyamine content increased gradually when chilling was increased to $400 \mathrm{CUs}$ and increased even more when the buds received enough chilling to break dormancy (600 CUs). The rapid increase in polyamine content may indicate the end of dormancy. Increased polyamine content is also observed in H. tuberosus (Bagni et al., 1980), Prunus spp. (Wang et al., 1985), and potato (Kaur-Sawhney et al., 1982) when dormancy is broken.

The polyamine biosynthetic inhibitors DFMA and DFMO), which inhibit arginine decarboxylase (ADC) and ornithine decarboxylase (ODC), respectively, had striking effects on bud break and bud growth. In buds treated with $10 \mathrm{nmol}$ of DFMA or DFMO

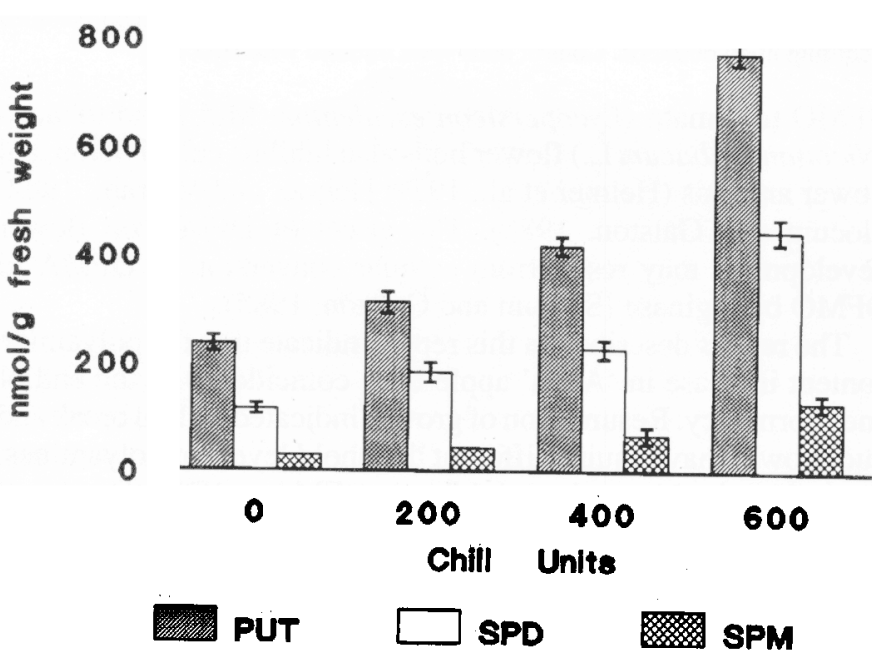

Fig. 1. Effect of chilling unit accumulation on putrescine, spermidine, and spermine content of apple flower buds. during cold treatment, bud break was significantly inhibited and growth was reduced compared with the control (Figs. 2-5). The greatest inhibition on bud break was observed when DFMO or DFMA was applied to the buds before they received any chilling or when chilled for only 200 CUs. DFMO or DFMA reduced bud break in concert with the decreased putrescine, spermidine, and spermine titers in buds (Figs. 68). These results may indicate that polyamine formation is essential for one or more metabolic processes involved in bud break. Bagni (1966) demonstrated that polyamides could help break dormancy and stimulate cell proliferation in tuber slices of $H$. tuberosus. The role of polyamides may be associated with the increased synthesis of DNA, RNA, and proteins associated with dormancy removal (Bagni et al., 1980; Wang et al., 1985).

'Anna' is an early flowering species that has a low chilling requirement. The flower buds of early flowering species can continue to respire through the alternate respiratory pathway, although the temperature is low. Using this alternate pathway, they generate enough energy to continue bud development and, consequently, during spring, they are ready to bloom earlier (Cole et al., 1982). It is clear that cell division in 'Anna' may have occurred before receiving 200 CUs. After receiving more than 400CUs, bud break became less sensitive to DFMO or DFMA. The inhibitory effect of DFMO or DFMA on bud break may be passed on to inhibit cell division. DFMO or DFMA had less effect on bud break when it was applied after cell division. Bagni and colleagues (Bagni, 1966; Bagni et al., 1980; Bagni and Serafini-Fracassini, 1985; Serafini-Fracassini et al., 1980) found that DFMO and DFMA suppressed cell division responses and that polyamides are generally necessary for cell division (Heimer, 1979). A blockage in polyamine synthesis is expected to inhibit mitosis. The inhibitory effect became less affective when DFMO or DFMA was applied to fully chilled buds (Fig. 2). This finding indicates that fully chilled buds may contain sufficient polyamides required for bud break. Because DFMO was more inhibitory than DFMA to bud break and bud development (Figs. 2-5), ODC may play a more important role than ADC in controlling metabolic processes correlated with bud break and bud growth. Enhanced activity of ODC has been reported when polyamine synthesis was accelerated during potato sprouting (Kaur-Sawhney et al., 1982).

With buds that received the full chilling requirement (600 CUs),

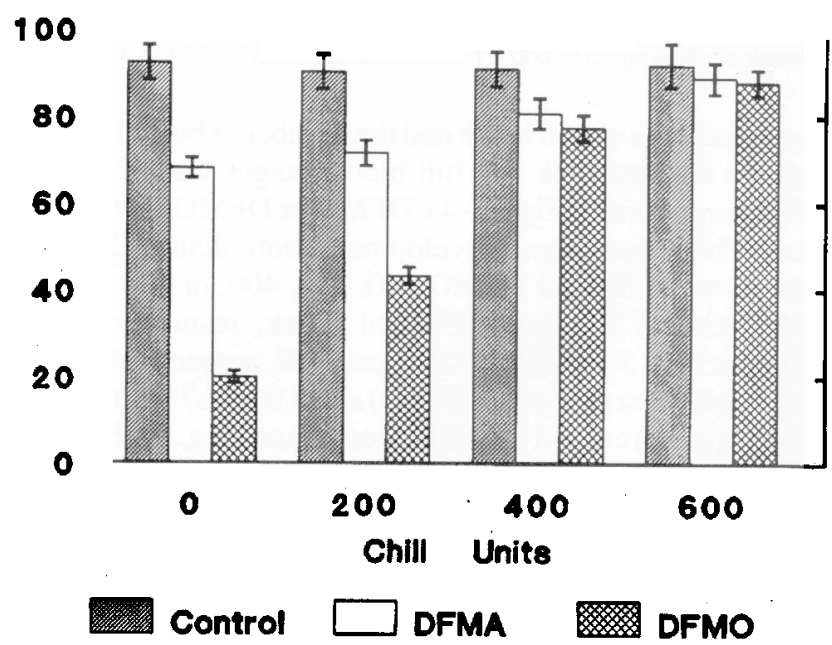

Fig.2. Effect of timing of polyamine inhibitor (DFMA or DFMO) treatment on bud break of apple flower buds. Ten nanomoles of DFMA or DFMO was applied after the buds received the indicated chilling units (CUs). Buds then resumed chilling up to 600 CUs. Control buds were injected with $\mathrm{H}_{2} \mathrm{O}$ only. 


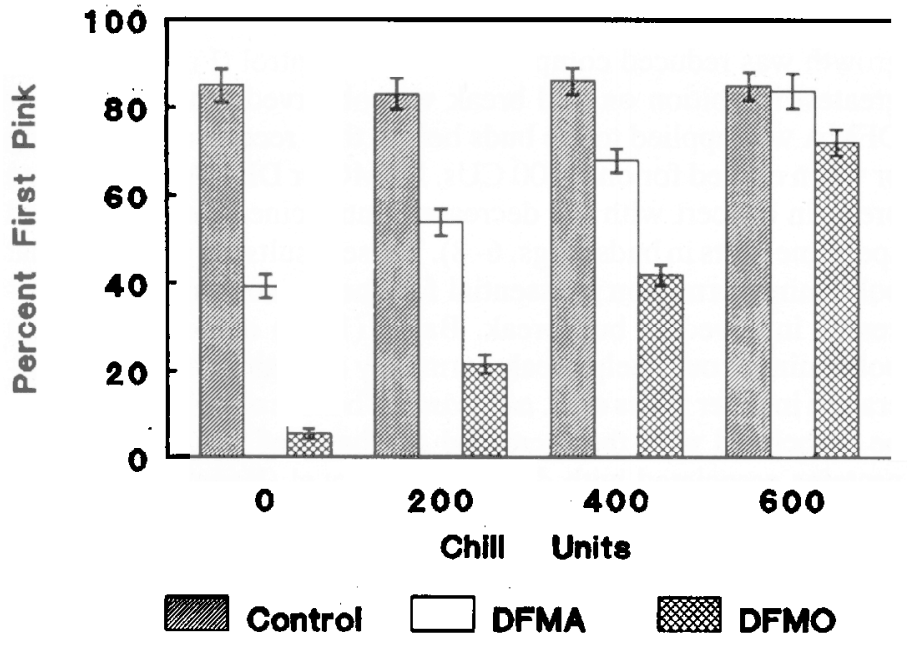

Fig.3. Effect of timing of polyamine inhibitor (DFMA or DFMO) treatment on the percent of buds reaching the first pink stage. Ten nanomoles of DFMA or DFMO was applied after the buds had received the indicated chilling units (CUs). Buds then resumed chilling up to $600 \mathrm{CUs}$. Control buds were injected with $\mathrm{H}_{2} \mathrm{O}$ only.

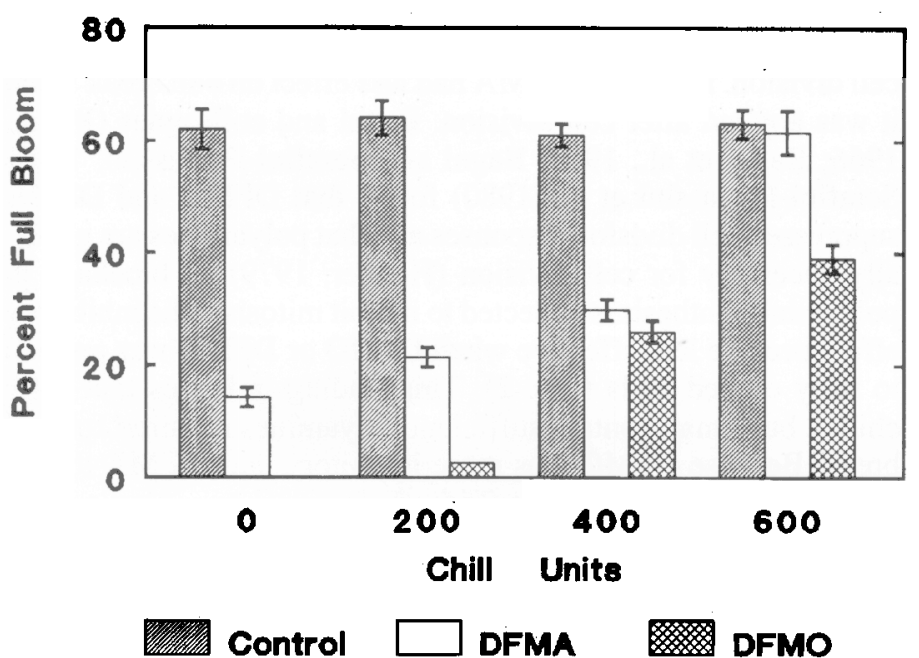

Fig.4. Effect of timing of polyamine inhibitor (DFMA or DFMO) treatment on the percent of buds reaching full bloom. Ten nanomoles of DFMA or DFMO was applied after the buds had received the indicated chilling units (CUs). Buds then resumed chilling up to $600 \mathrm{CUs}$. Control buds were injected with $\mathrm{H}_{2} \mathrm{O}$ only.

the percentage of bud break and the number of buds that developed beyond the first pink and full bloom stages was $92 \%, 85 \%$, and $62 \%$, respectively (Figs. 2-4). DFMA or DFMO seemed to inhibit flower bud growth and development more than bud break. Buds treated with $10 \mathrm{nmol}$ DFMO at O, 200, 400, or 600 CUs showed $20 \%, 43 \%, 77 \%$, and $88 \%$ bud break, respectively (Fig. 2), whereas only $5.6 \%, 22 \%, 42 \%$, and $72 \%$, respectively, developed beyond the first pink stage (Fig. 3) and $0.0 \%, 2.7 \%, 26 \%$, and $39 \%$, respectively, reached the full bloom stage (Fig. 4). Flower length was also inhibited by DFMO and DFMA (Fig. 5). DFMO was more inhibitory than DFMA. The polyamine requirement seemed to be much higher for bud growth and development than for differentiation and bud break. Wang et al. (1985) found that the ratio of polyamides (nmol) to DNA $(\mu \mathrm{g})$ increased from $2.78 \mathrm{in}$ differentiating dormant buds to 5.32 in actively growing buds of $P$. avium and from 3.86 to 5.56 in $P$. serrulata. Polyamides increased during differentiation, but only slightly, and the increase was rapid only when active growth was resumed. Applying DFMA and

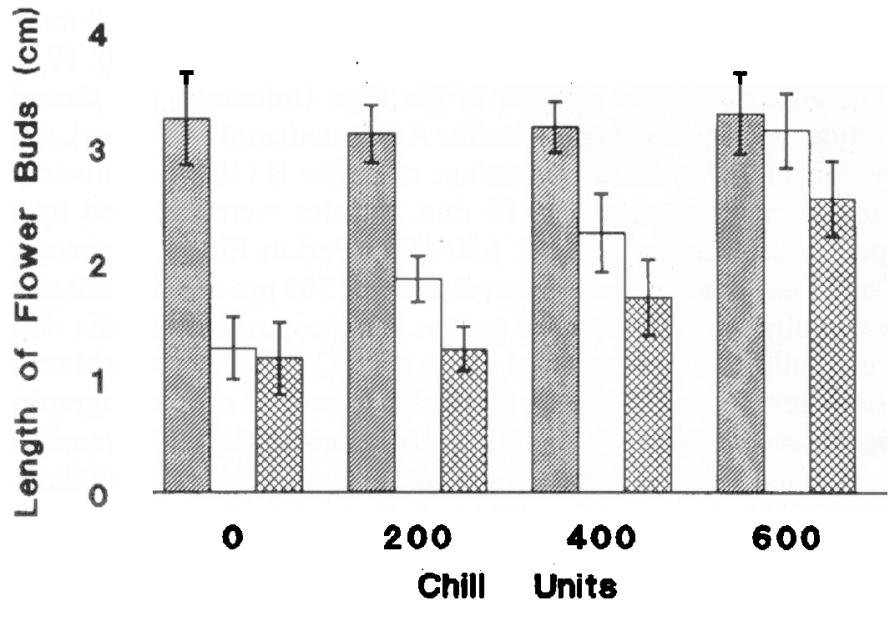

Control $\square$ DFMA DFMO

Fig.5. Effect of timing of polyamine inhibitor (DFMA or DFMO) treatment on the length of flower buds. Ten nanomoles of DFMA or DFMO was applied after the buds had received the indicated chilling units (CUs). Buds then resumed chilling up to 600 CUs. Control buds were-injected with $\mathrm{H}_{2} \mathrm{O}$ only.
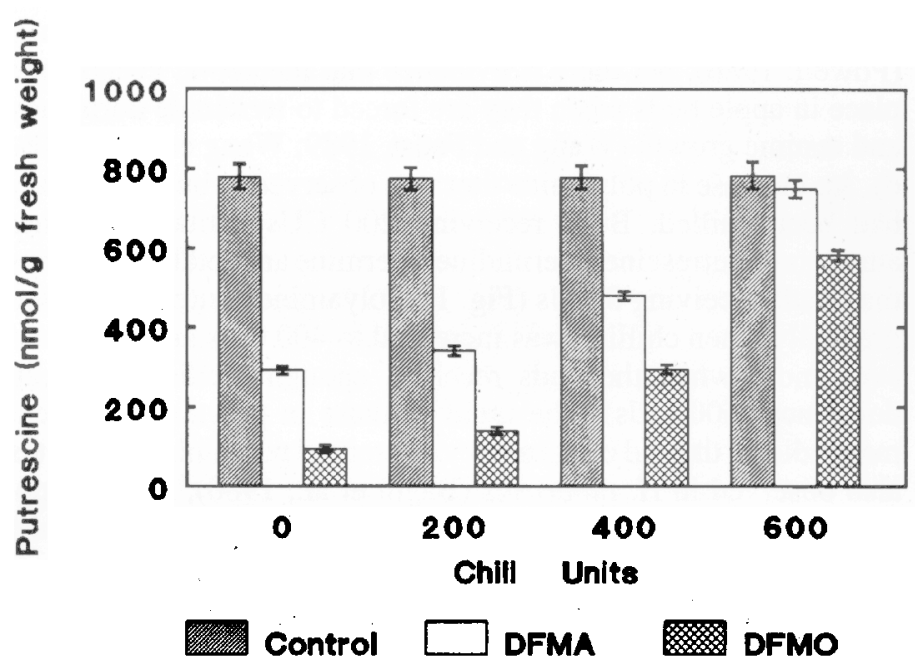

Fig.6. Effect of timing of polyamine inhibitor (DFMA or DFMO) treatment on putrescine concentration. Ten nanomoles of DFMA or DFMO was applied after the buds had received the indicated chilling units (CUs). Buds then resumed chilling up to $600 \mathrm{CUs}$. Control buds were injected with $\mathrm{H}_{2} \mathrm{O}$ only.

DFMO to tomato (Lycopersicon esculentum Mill.) and tobacco (Nicotiana tabacum L.) flower buds also inhibits cell division and flower anthesis (Heimer et al., 1979; Heimer and Mizrahi, 1982; Slocum and Galston, 1985). The effect of DFMA on flower development may result from cellular conversion of DFMA to DFMO by arginase (Slocum and Galston, 1985).

The results described in this report indicate that the polyamine content increase in 'Anna' apple buds coincides with the end of endodormancy. Resumption of growth indicated by bud break and bud growth may require different threshold levels of polyamides. The polyamine biosynthetic inhibitors DFMA and DFMO reduced endogenous polyamine content and inhibited bud break and bud growth. DFMO had no effect on bud break when it was applied after 'Anna' buds had received more than 400 CUs. DFMA also inhibited bud break and bud growth, but to a lesser degree, a result suggesting that the inhibitor might be converted to DFMO by the high arginase activity present in the buds (Slocum and Galston, 


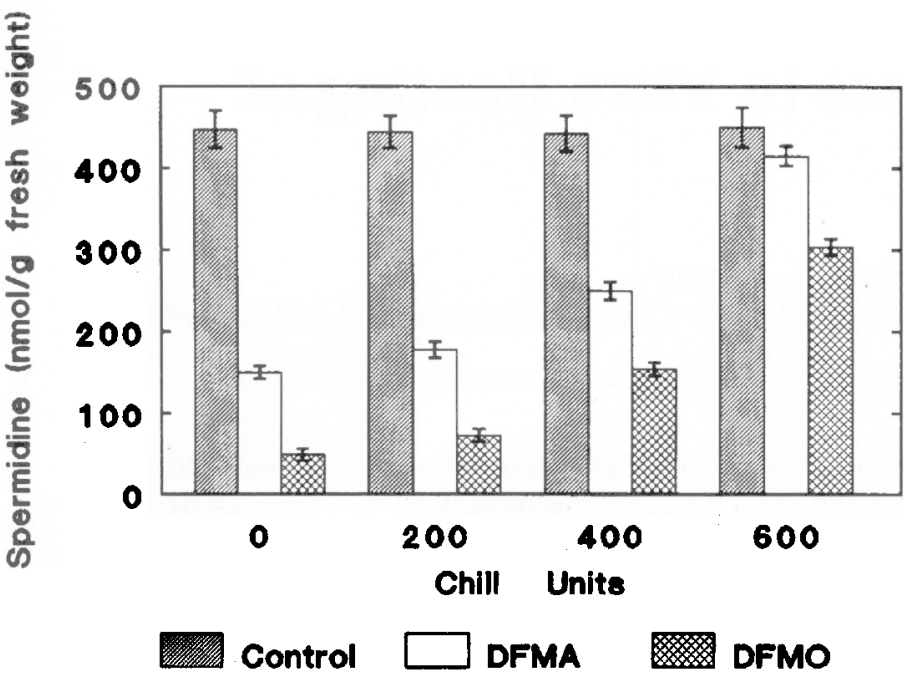

Fig.7. Effect of timing of polyamine inhibitor (DFMA or DFMO) treatment on spermidine concentration. Ten nanomoles of DFMA or DFMO was applied after the buds had received the indicated chilling units (CUs). Buds then resumed chilling up to 600 CUs. Control buds were injected with $\mathrm{H}_{2} \mathrm{O}$ only.

1985). Polyamides seem to regulate some part of bud development, but their precise role remains elusive.

\section{Literature Cited}

Abbott, D.L. 1970. The role of budscales in the morphogenesis and dormancy of the apple fruit bud, p. 65-82. In: L.C. Luckwill and C. Cutting (eds.). Physiology of tree crops. Academic Press, London.

Bagni, N. 1966. Aliphatic amines and a growth factor of coconut milk stimulate cellular proliferation of Helianthus tuberosus in vitro. Experiential 22:732-736.

Bagni, N., B. Malucelli, and P. Torrigiani. 1980. Polyamines, storage substances and abscisic acid-like inhibitors during dormancy and very early activation of Helianthus tuberosus tissue slices. Physiol. Plant. 49:341-345.

Bagni, N. and D. Serafini-Fracassini. 1985. Involvement of polyamines in the mechanism of break of dormancy in Helianthus tuberosus. Bul. Soc. Bot. (France) 132:119-125.

Cole, M.E., T. Solomos, and M. Faust. 1982. Growth and respiration of dormant flower buds of Pyrus communis and Pyrus calleryana. J. Amer. Soc. Hort. Sci. 107:226-231.

Evans, P.T. and R. Malmberg. 1989. Do polyamides have role in plant development? Annu. Rev. Plant Physiol. 40:235-269.

Faust, M. and S.Y. Wang. 1992. Polyamines in horticulturally important plants. Hort. Rev. 14:303-356.

Galston, A.W. 1983. Polyamines as a modulator of plant development. Bioscience 33:382-388.

Heimer, Y. M., Y. Mizrahi, and U. Bachrach. 1979. Ornithine decarboxylase activity in rapidly proliferating plant cells. Federation European Biochem. Soc. Lett. 104:146-149.

Heimer, Y., and Y. Mizrahi. 1982. Characterization of ornithine decarboxylase of tobacco cells and tomato ovaries. Biochem. J. 201:373-376.

Kaur-Sawhney, R., L.M. Shih, and A.W. Galston. 1982. Relation of polyamine biosynthesis to the initiation of sprouting in potato tubers. Plant Physiol. 69:411-415.

Kramer, G.F. and C.Y. Wang. 1989. Correlation of reduced chilling injury with increased spermine and spermidine levels in zucchini squash.

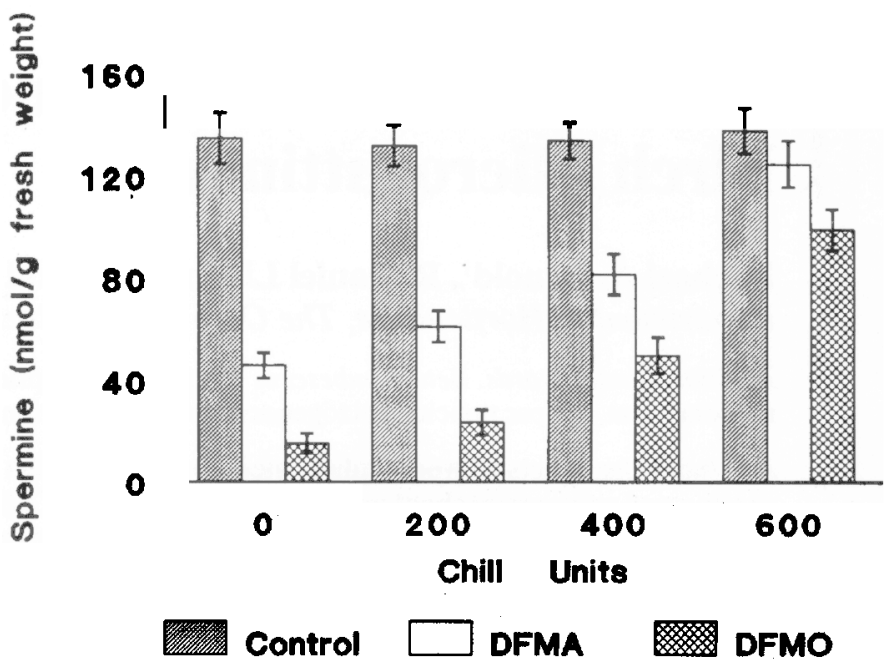

Fig.8. Effect of timing of polyamine inhibitor (DFMA or DFMO) treatment on spermine concentration. Ten nanomoles of DFMA or DFNO was applied after the buds had received the indicated chilling units (CUs). Buds then resumed chilling up to 600 CUs. Control buds were injected with $\mathrm{H}_{2} \mathrm{O}$ only.

Physiol. Plant. 76:479-484.

Lang, G.A., J.D. Early, N.J. Arroyave, R.L. Darnell, G.C. Martin, and G.W. Stutte. 1985. Dormancy: Toward a reduced, universal terminology. HortScience 20:809-812.

Powell, L.E. 1986. The chilling requirement of apple and its role in regulating time of flowering in spring in cold winter climates. Acta Hort. 179:129-133.

Serafini-Fracassini, D., N. Bagni, P.G. Cionini, and A. Bennici. 1980. Polyamides and nucleic acids during the first cell-cycle of Helianthus tuberosus tissue after the dormancy break. Planta 148:332-337.

Slocum, R.D. and A.W. Galston. 1985. In vivo inhibition of polyamine biosynthesis and growth in tobacco ovary tissues. Plant Cell Physiol. 26: $1519-1526$.

Wang, S. Y., M. Faust, and G.L. Steffens. 1985. Metabolic changes in cherry flower buds associated with breaking of dormancy in early and late blooming cultivars. Physiol. Plant. 65:89-94.

Wang, S.Y. and M. Faust. 1989. Metabolic activities associated with flowering in deciduous fruit trees, p. 10-19. In: W.N. Chang and J. Bay-Petersen (eds.). Off-season production of horticultural crops. Food and Fert. Technol. Ctr. for the Asia and Pacific Region, Taipei, Taiwan. Book Ser. 41

Wang, S. Y., H.J. Jiao, and M. Faust. 1991a. Changes in metabolic enzyme activities during thidiazuron-induced lateral budbreak of apple. HortScience 26:171-173.

Wang, S.Y., H.J. Jiao, and M. Faust. 1991b. Changes in superoxide dismutase activity during thidiazuron-induced lateral bud-break of apple. HortScience 26: 1202-1204.

Wang, S.Y. H.J. Jiao, and M. Faust. 1991c. Changes in the activities of catalase, peroxidase, and polyphenol oxidase in apple buds during bud break induced by thidiazuron. J. Plant Growth Regulat. 10:33-39.

Wang, S. Y., H.J. Jiao, and M. Faust. 1991d. Changes in ascorbate, glutathione, and related enzyme activities during thidiazuron-induced bud break of apple. Physiol. Plant. 82:231-236.

Westwood, M.N. 1978. Temperate-zone pomology. Freeman, San Francisco.

Zimmerman, R.H. and M. Faust. 1969. Pear bud metabolism: Seasonal changes in glucose utilization. Plant Physiol. 44:1273-1276. 